\title{
Entre lo público y lo privado: una contribución al estudio de la tiranía griega
}

\author{
Mª Dolores Dopico CAínzos
}

\begin{abstract}
RESUMEN ABSTRACT

En este artículo se muestra la This article shows the important importante función que adquirió la hospitalidad a manos de algunos tiranos griegos. A través de varios ejemplos de tiranos pertenecientes a diversas épocas y poleis, podemos ver que una relación estrictamente privada fue utilizada para crear alianzas con las élites y los gobernantes de otros Estados, griegos o no. Esto les permitió consolidar o acrecentar su poder. function which hospitality had for some Greek tyrants. With the help of several examples of tyrants belonging to different periods and poleis, we can see that a strict private relation was used to establish alliances with the elites or the rulers of other communities, which could be either Greek or not. This allowed them to consolidate or increase their power.

\section{PALABRAS CLAVE}

Hospitalidad, tiranía griegã.
\end{abstract}

Sabido es que el intento de trazar un panorama genérico de la tiranía en el mundo griego es una tarea difícil para el historiador actual. No podemos en este caso - como en tantos otros - culpar exclusivamente a la escasez de las fuentes disponibles, a su transmisión de una información parcial, tardía o desigual de los tiranos. Es cierto que de algunos - los más- nos dejan entrever tan sólo sus nombres o unas cuantas anécdotas de su vida, en algunos casos intrascendentes, en tanto que de otros - una 
minoría - nos narran algunos aspectos de su acceso al poder o de sus medidas de gobierno. Pero estas lagunas en la información, con ser evidentemente importantes, no son la causa única de la dificultad que encontramos a la hora de esbozar una visión genérica de esta figura política, pues también debemos tener en cuenta la propia naturaleza de la tiranía. La enorme extensión temporal de esta forma de gobierno, que abarca desde época arcaica hasta la helenística, implica una lógica diversidad, pues los tiranos surgen en contextos históricos desiguales. Nos encontramos, así, ante una obvia heterogeneidad en la finalidad, intereses, gobierno $u$ orígenes de cada uno, por lo que no es de extrañar los problemas que plantea su sistematización ${ }^{1}$.

Mi intención en este artículo es detenerme en uno de los pocos aspectos comunes a todos ellos, según han señalado la mayoría de los historiadores. La característica básica que se puede atribuir a todos los tiranos, por encima de todas estas diferencias, es su poder personal. Independientemente de las medidas concretas de gobierno, de las distintas formas de acceder al poder o de los recursos utilizados para mantenerse en el mismo, todos ellos - cualquiera que sea la época en la que viven- se caracterizan por detentar un poder personal, al margen de las instituciones y controles de la polis, hasta el punto de ser equiparados a una forma de monarquía ${ }^{2}$.

Muchos son los aspectos en los que se manifiesta este poder personal, que van desde la forma en que lo ejercen al margen del control ciudadano, hasta los simbolos que lo rodean, que por otra parte son suficientemente conocidos y en los que no me detendré. Trataré tan sólo un aspecto de este poder personal, en el que unas relaciones estrictamente privadas - las de hospitalidad- son utilizadas por los tiranos en la esfera pública, convirtiéndolas en un instrumento político en su propio beneficio. La hos-

Así lo podemos ver desde las monografías clásicas de A. ANDREWES (The Greeks Tyrants, Londres 1956) y CL. Mossé (La tyrannie dans la Grèce antique, París 1969) en las que ya se expresaban los problemas que presentaban el estudio de la tiranía y la dificultad de establecer unas características comunes a todos ellos, hasta los trabajos recientes, como nos muestran las palabras de P. OLIVA: It is not surprising, then, that the early tyranny constitutes one of the most problematical questions in Greek History of the seventh and sith centuries. This is true both of the view of the phenomenon itself adopted by different scholars and that of the rule of different tyrants («The Early Tyranny», Dialogues d'Histoire Ancienne 8 1982, pág. 363). En el mismo sentido, vid. R. Drews, "The first Tyrants in Greece», Historia 21 1972, págs. 129-144.

2 La expresión de Mossé es más tajante: nos encontraríamos ante una especie de «monarca absoluto" (o.c. pág. 203). Las opiniones de sus colegas no difieren demasiado, desde Andrewes que llega a hablar de algo similar a los "dictadores» actuales (o.c. pág. 7) hasta la opinión más moderada del reciente trabajo de J.F. McGlew, Tyranny and Political Culture in Ancient Greece, N. York 1993, pág. 5. 
pitalidad es una relación ampliamente conocida y extendida entre otros pueblos antiguos, y que aparece bien reflejada en las fuentes griegas. Sus especiales características la convierten en un excelente recurso para consolidar o acrecentar el poder de los tiranos. A éstos ya no les interesa el sentido primigenio de la hospitalidad, sino las obligaciones que contraían ambos huéspedes, las cuales la convertían en un valioso instrumento político personal que los tiranos no dudaron en emplear, como veremos a continuación. Utilizaré para ello los ejemplos de las relaciones que mantuvieron siete tiranos bien diversos pertenecientes a distintas épocas ${ }^{3}$, entre los que se encuentran algunos de los «demagogos» arcaicos de los que más información disponemos, como Periandro de Corinto, Trasíbulo de Mileto, Polícrates de Samos y los Pisistrátidas de Atenas. Otros dos pertenecen al tipo de tiranos sicilianos - Hierón y Terílo- con un poder de naturaleza distinta a los anteriores, basado en su fuerza militar. A ellos se añade un ejemplo de tirano impuesto por los persas en su intento de controlar las regiones griegas de Asia Menor, Histieo de Mileto.

Sabemos que las relaciones de hospitalidad surgen como un intento de suplir la insuficiencia de los recursos jurídicos a los que pueden recurrir los individuos que se encuentran en un Estado ajeno, en el que son considerados extranjeros. La falta de protección pública, por una parte, y la necesidad de cubrir unas necesidades elementales que surgen inevitablemente durante su esiancia, por otra, favorecen el desarrollo de relaciones privadas que actúan de manera sustitutoria. Sin embargo este primer nivel en el que se desarrolla la hospitalidad tiene poco que ver con la utilización que de ella hacen los tiranos, pues se vincula más bien a las obligaciones que se derivan de ella. Sabemos que los huéspedes son individuos que pertenecen a grupos sociales similares, y que desarrollan lazos de amistad que conllevan ayudas o favores muy diversos. El hecho de que estas relaciones sean, además, hereditarias, fortalece las relaciones entre familias que gozan de un cierto prestigio y poder en sus respectivas comunidades. Hay que tener en cuenta, igualmente, que los pactos carecen de controles públicos, y su sanción y garantías se sitúa fuera de los controles oficiales. Todo ello favorece su utilidad como instrumento político, extendiendo así los motivos para invocar la hospitalidad a otros aspectos que ya no tienen nada que ver con el alojamiento o la protección jurídica. Con

3 Además de las que aquí se verán, hasta nosotros han llegado otros testimonios de relaciones de hospitalidad que tienen como contrayente a un tirano, por ejemplo las que mantuvieron con poetas o filósofos, como Hierón de Siracusa con Píndaro (p. 3.69) o Dionisio de Siracusa con Platón y otros filósofos (Plu. Dio 22.1; Pl. Ep. 3.316c; Plu. Dio 18.2). Su sentido y finalidad, como es evidente, son bien diferentes a las que aquí trataré, por lo que no las analizaré en este trabajo. 
estos pactos los tiranos ya no pretenden ser «bien acogidos» en un hipotético desplazamiento a otra comunidad, sino crear vínculos personales profundos que puedan ser utilizados politicamente a su favor de distintas maneras, como veremos a continuación. Empezaré por mostrar cómo las citadas características - la categoría social de los contrayentes, la naturaleza hereditaria de los pactos y la ausencia de controles públicos- fue aprovechada por los tiranos, tal como muestran los textos disponibles, para ver posteriormente la utilización concreta que hicieron de ellos en cada caso.

Sabemos que las relaciones de hospitalidad -cualesquiera que fueran sus protagonistas - se establecen entre individuos «iguales». En nuestro caso esto significa que un tirano, debido a la posición que ocupa en la polis, debe contraerlas con individuos sobresalientes por su riqueza, sus relaciones familiares o su poder. De hecho esto supone crear unas redes de amistades con las élites dirigentes o con los gobernantes de los distintos Estados, lo que permitirá apelar a su ayuda cuando a cada tirano le convenga, como veremos más adelante. A la hora de concretarse en la práctica, estas alianzas admitían una gran diversidad de soluciones, pues, se podían realizar con un solo individuo o con varios, con personas que detentaban un poder institucionalizado o de «facto", con griegos o con extranjeros, aunque siempre, como veremos a continuación, se buscaba lo más ventajoso para el tirano.

La mejor expresión de esta red de relaciones entre individuos con un poder de idéntica posición, la encontramos precisamente en la que mantienen dos tiranos entre sí. No es, por otra parte, nada sorprendente, pues el establecimiento de vínculos personales y amistosos entre ellos es una práctica frecuente, que no se limita a la hospitalidad. Las buenas relaciones de amistad que mantienen, los matrimonios entre sus familias como medio de reforzarlas, o los apoyos mutuos para alcanzar o consolidar su poder, no son más que algunos ejemplos ${ }^{4}$. Dentro de esta amistad especial y que supone una profundización de las mismas, se puede enmarcar

\footnotetext{
4 Baste recordar la estrecha relación que mantenían entre sí tiranos tan conocidos como Polícrates de Samos, Periandro de Corinto y Lígdamis de Naxos. En el caso de este último hay que añadir los estrechos vínculos que mantuvo con Pisístrato de Atenas que encuentran su máxima expresión en el apoyo mutuo que se prestaron para acceder a la tiranía. Primero fue Lígdamis el que sostuvo a Pisístrato en su segundo intento de hacerse con el poder en Atenas, a cambio de lo cual éste le ayudó a alzarse con la tiranía de Naxos (Hdt. 1.61). Para el análisis del relato de Herodoto sobre la ascensión al poder de Pisístrato, sus paralelos literarios y su utilización política vid. W.R. ConNor, "Tribes, Festivals and Processions in Archaic Greece», JHS 107 1987, págs. 40-50 y B.M. LARELLE, "The compleat Angler: Observations on the Rise of Peisistratos in Herodotus" (1.59-64), CQ 41 (2) 1991, págs. 317-324.
} 
la hospitalidad que, según Herodoto, mantenían Periandro de Corinto y Trasíbulo de Mileto ${ }^{5}$. Ambos son dos buenos ejemplos de tiranos «demagogos arcaicos», que ejercen su poder en dos poleis bien destacadas en estos momentos por su prosperidad económica ${ }^{6}$. Sin embargo la información que tenemos sobre ellos es bastante desigual, pues en tanto $\mathrm{Pe}$ riandro es uno de los tiranos mejor conocidos, de Trasíbulo, el primer tirano jonio del que tenemos noticia, sólo disponemos de algunas anécdotas que relatan su relación con Periandro. Aparte de la más conocida, que alude a los consejos sobre cómo controlar mejor a la aristocracia ${ }^{7}$, hay otra previa en la que se manifiesta la utilidad política de los lazos de hospitalidad. La especial amistad entre ambos es la causa de que Periandro preste una valiosa ayuda que servirá para solucionar el largo enfrentamiento bélico que oponía a los lidios con Mileto ${ }^{8}$.

En otros casos las relaciones de hospitalidad son más amplias, y afectan a más de una persona, como vemos en las que mantuvo Histieo de Mileto con los naxios. Con Histieo nos hallamos ante un tipo de tirano totalmente alejado de los "demagogos» arcaicos que acabamos de ver, que habían surgido en un contexto de crisis de la polis ${ }^{9}$. Representa perfectamente a ese conjunto de dirigentes de Asia Menor que acceden al poder y se mantienen en él gracias al apoyo persa ${ }^{10}$. Es sabido que a lo largo de

\footnotetext{
5 La mayoría de los textos sobre la tiranía que utilizaré en este trabajo son de Herodoto. El significado y utilización de este término en su obra ha sido discutido en ocasiones, vid. el análisis de esta cuestión en A. FefRIL, «Herodotus on Tyranny", Historia 27 1978, págs. 385-398.

6 La prosperidad económica de Corinto en época de la tiranía es bien conocida, como también lo es que la política exterior de Periandro persigue unos claros intereses comerciales y la expansión colonial. Podemos señalar, enre otras, la construcción de un nuevo puerto que no tenía una finalidad estratégica o militar, sino que estab claramente dedicado a los navíos comerciales. Sobre estos aspectos de su política económica, así como los bienes exportados, rutas y líneas del comercio corintio en esta época, vid. J.B. Salmon, Wealthy Corinth. A History of the city to $338 B C$, Oxford 1986, págs. 134 ss.

7 Se trata de la conocida parábola de las espigas que ejemplifica cómo deben tratar los tiranos a la aristocracia, sobre la que hay dos versiones. En la transmitida por Herodoto (5.92) $\mathrm{Pe}-$ riandro es quien pide consejo a Trasíbulo, en tanto según Aristóteles ( $P o l$. 1284a; 1311a) ocurre justamente al contario. Sobre la naturaleza del poder de Periandro y su relación con Polícrates, vid. H. Berve, Die Tyrannis bei den Griechen (I), Munich 1967, pág. 19 ss.

8 Vid. el texto en la nota 35.

9 En tanto los tiranos arcaicos aparecen como consecuencia de los problemas de cada comunidad y son, por tanto, una figura que obedece a su propia evolución histórica, los sostenidos por los persas son fruto de una imposición externa, y por tanto ajenos a su evolución. Sobre las peculiaridades de estos tiranos, que surgen en una época en que ya no existen en el resto de Grecia, el sentimiento antipersa que generan y su importancia dentro de la historia griega, vid. M.M. Austin, «Greek Tyrants and the Persians», CQ 40 (2) 1990, págs. 289-306.

${ }_{10}$ Como bien señalaba el propio Histieo, cuando decía que todos dependían de Darío (Hdt. 4.137.2). Efectivamente es sabido que los persas utilizaron una gran variedad de recursos para el control de los territorios que paulatinamente fueron sometiendo --tiranos, sátrapas...- pero siempre
} 
todo el Imperio las autoridades persas pretendieron disponer de unos administradores fieles que realizasen ciertas funciones básicas para el Estado, como eran, entre otras, la recaudación del tributo ${ }^{11}$. Los tiranos como Histieo cumplieron esa función, aunque en este caso el trato que recibió Mileto era bastante bueno. La razón hay que buscarla en su apoyo a Ciro y a Creso, que le había permitido no soportar determinadas cargas impuestas a otros, como las levas o el tributo real, con lo que disfrutaba de una posición más ventajosa dentro de las poleis griegas ${ }^{12}$. Todo ello favoreció la prosperidad de su comercio que seguía manteniendo con diversos Estados, que iban desde Egipto, hasta Síbaris, Eretria o Atenas.

Si el conocimiento de este contrayente de la hospitalidad no ofrece problemas, la identificación de la otra parte no es, en principio, tan clara, pues a lo largo de este episodio aparece genéricamente denominada como los "exiliados naxios" o los $\ddot{\alpha} v \delta \rho \varepsilon \varsigma \tau \widetilde{\omega} v \pi \alpha \chi \varepsilon \omega^{\omega} \omega{ }^{13}$. Este término griego aparece aplicado por Heródoto, en otros pasajes de su obra, a los grupos oligárquicos que controlan el poder en sus comunidades, como los hippobotas de Calcidia o los oligarcas de Egina ${ }^{14}$. Podemos suponer, por tanto, que Histieo mantenía relaciones de hospitalidad con destacados miembros de la aristocracia de la isla, con aquéllos que la habían dominado oligarquicamente hasta fechas recientes. Su poder se había forjado tras la caída de la tiranía, que había gobernado durante varios años Naxos y cuyo más destacado representante había sido Lígdamis. La desaparición

con la finalidad básica de cobrar el tributo, pues su intervención en otros aspectos internos que no suponian una amenaza a su Imperio era bastante menor. Sobre la relación con las poleis griegas, vid. A.R. BunN, «Persia and the Greeks", en I. Gershevitch (ed.), The Cambridge History of Iran (II): The Median and Achaemenid Periods, Cambridge 1985, pp. 292-391. Sobre las satrapias, poder de los sátrapas y su relación con el poder central desde las reformas de Darío I, vid. T. Petit, Satrapes et Satrapies dans l'empire achéménide de Cyrus le Grand à Xerxès I, París 1990.

11 Sobre la utilización concreta de los tiranos griegos, en este aspecto, así como las formas y la cantidad del tributo que se cobraba a las poleis de Asia Menor, vid. R.N. Frye, The History of Ancient Iran, Munich 1984, págs. 116 ss.

12 La posición de Mileto era especialmente privilegiada dentro del conjunto de poleis jonias, que por lo demás eran totalmente diversas y carecían de una política común para hacer frente a los poderes que amenazaban su independencia. La liga jonia no tenía practicamente más cometidos que la realización de ciertos festivales y ritos como la celebración de la Panionia, vid. sobre ello D. LATEINER, «The Failure of the lonian Revolt», Historia 31 1982, págs. 129-160. No todas las comunidades, sin embargo, se encontraron ante una situación tan ventajosa como Mileto, pues la conquista de Jonia fue bastante brutal, por lo que se ha discutido mucho sobre la posibilidad de que la decadencia de esta región - política, cultural y económica - se deba a este dominio. Sobre todo ello, así como las graves consecuencias de la conquista persa en su relación con Grecia, vid.

O. PICARD, Les Grecs devant la menace perse, París 1980, págs. 81 ss.

13 Vid. nota 46.

14 Vid. las referencias en W.W. How, J. WELLS, A commentary on Herodotus (vol. II), Oxford 1912, pág. 11. 
de esta forma de gobierno condujo al predominio de la oligarquía, parece ser que no por mucho tiempo, debido a razones políticas y económicas. Sobre el 505 a.C. Naxos perdió su papel privilegiado en el Mediterráneo, lo que se tradujo en problemas económicos y coincidiendo con esta situación se produjo un enfrentamiento entre las facciones aristocrática y la demócrata, que se saldó con la victoria de los segundos y la expulsión de los oligarcas ${ }^{15}$. Es en este contexto cuando se produce el episodio narrado por Heródoto, quien menciona a ciertos individuos sobresalientes, miembros de esa oligarquía, que habiendo sido desterrados por el régimen democrático se dirigen a Mileto para invocar la ayuda de su huésped Histieo. El texto no nos permite saber cuál es la extensión exacta de estas relaciones de hospitalidad, si afectan a una o varias familias oligárquicas, pero en cualquier caso las consecuencias son las mismas que las vistas en el caso de Trasíbulo. Aunque en el caso de éste se trataba de una sola persona que detentaba el gobierno de la polis, en el de los naxios nos encontramos ante el grupo rector de la misma, lo que habría supuesto idéntica alianza política en tanto siguiera controlando el poder.

Pero hay otras ventajas en la elección del segundo contrayente del pacto, además de las que acabamos de ver. No podemos olvidar que nos encontramos ante una institución que no es exclusivamente griega, pues en otros pueblos se conocían y practicaban relaciones semejantes ${ }^{16}$. Esto implica que los tiranos podían extender sus influencias y amistades a Estados no griegos, con instituciones y formas organizativas muy diferentes, pero que presentaban un alto interés como potenciales aliados. Los principios que rigen la elección del otro contrayente, sin embargo, siguen siendo los que ya hemos visto antes. Nos encontramos con individuos que, por encima de todo, tienen un poder significativo en su comunidad. Uno de los ejemplos más claros es el pacto de hospitalidad entre Polícrates de Samos y el faraón Amasis ${ }^{17}$. A diferencia de otros tiranos, Polícrates es

15 Sobre la tiranía de Lígdamis y su desaparición, vid. Mossé o.c. p. 20 ss.

16 Numerosos ejemplos de pactos entre griegos y bárbaros aparecen citados en la monografía de G. Herman, Ritualised Friendship in the Greek City, Cambridge 1987.

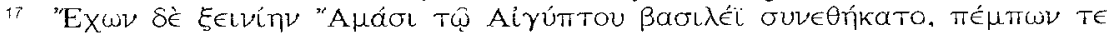

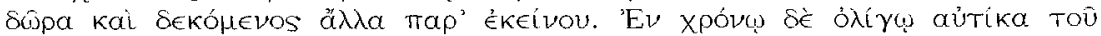

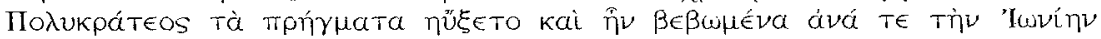

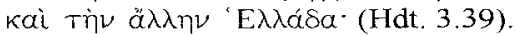

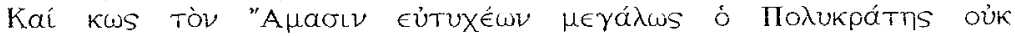

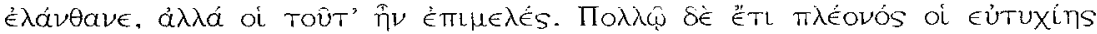

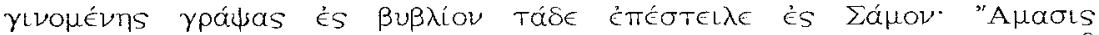

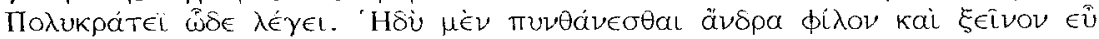

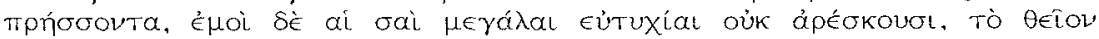

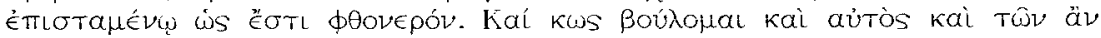


uno de los más conocidos gracias a las múltiples anécdotas conservadas sobre su vida y gobierno, que nos transmiten la imagen de uno de los gobernantes más poderosos de su época, acorde también con la importancia de Samos. El otro contrayente, en cambio, se encontraba en una situación política bien distinta. Amasis tiene que hacer frente al desmoronamiento del poder egipcio, que se manifiesta especialmente en sus dificultades para detener la agresión persa. Aunque conseguirá impedir la sumisión del Estado ante los ataques de Nabucodonosor II y mantener su independencia, ésta sólo se mantendrá mientras viva, y a su muerte Egipto entrará a formar parte del Imperio Aqueménida.

A la hora de realizar el pacto de hospitalidad es evidente que el único contrayente verdaderamente útil para Polícrates sólo podía ser el faraón, dada la naturaleza de su poder y las funciones que asumía. En un Estado de las características del egipcio no existe otra posibilidad de tratar con magistrados o instituciones cuya influencia se tradujese, en un plano práctico, en ayuda militar, política o económica ${ }^{18}$. Sólo el faraón tenía capacidad para intervenir en estas cuestiones, por tanto Polícrates acude a una relación estrictamente personal para concluir una alianza que lo beneficia a él, pero también a Samos en el plano económico ${ }^{19}$. Pero los otras casos en que se acude a contrayentes extranjeros no son menos reveladores, como ocurre con los tiranos sicilianos Terílo de Himera y Hierón de Siracusa. El primero era huésped del cartaginés Amílcar, perteneciente a la poderosa familia de los Magónidas ${ }^{20}$. De nuevo su elección parece la mejor, sobre todo si recordamos que los Magónidas, junto con los Bárquidas, son las

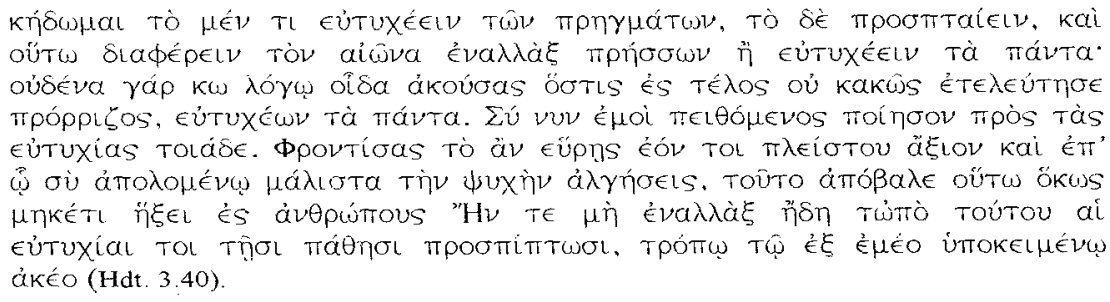

18 Es bien sabido que el poder del faraón abarca todos los aspectos administrativos y organizativos de Egipto, pero así como muchos de ellos tiene que delegarlos forzosamente para que sean operativos, en el caso de la política exterior sigue manteniendo un control pleno. Esto se puede ver especialmente en la correspondencia oficial que mantiene con otros reyes o gobernantes, que a pesar de encuadrarse en las relaciones internacionales siguen manteniendo la forma de una correspondencia personal, como señalan G. Husson y D. VALBELLE, L'Etat et les institutions en Egypte des premiers pharaons aux empereurs romains, París 1992, págs. 21ss; 31 ss. Sobre Polícrates vid. infra nota 38 .

19 Sobre la versión que da Herodoto de este pacto y su desarrollo vid. B.M. MitCHELL, «Herodotus and Samos", JHS 95 1975, págs. 75-91.

20 Vid. el texto en nota 43. 
dos familias más influyentes de Cartago y están indisolublemente unidas al proceso de expansión del Estado ${ }^{21}$. Su prestigio va unido a su relación con el ejército, pues Magón es esencialmente un jefe militar y su posición e influencia en Cartago se debía a esta circunstancia, teniendo en cuenta la peculiaridad de la estructura del ejército cartaginés, que a diferencia de lo que es común en Grecia está formado por mercenarios. Es significativo que Terílo no realiza un pacto con un magistrado cualquiera que representa a Cartago, sino con alguien que verdaderamente tiene un poder que se puede manifestar en una ayuda concreta - la militar- como se verá más adelante ${ }^{22}$.

El caso de Hierón de Siracusa es, en este sentido, muy parecido al de Terílo, si bien el otro contrayente procede del mundo helenístico, pues se trata del rey Pirro ${ }^{23}$. El interés por su hospitalidad es evidentemente personal. Hierón no busca una alianza con un Estado griego determinado, sino con un hombre en concreto que tiene un poder sobresaliente y podía serle útil para mantener su posición en Sicilia. Efectivamente en estos momentos Pirro no tiene detrás un Estado poderoso, cuyo peso pueda ser decisivo en ciertos asuntos políticos, pues sus intentos de controlar Macedonia y Tesalia se habían saldado con un claro fracaso ${ }^{24}$. Lo que hacía interesante su alianza era su poderoso y numeroso ejército dotado de efectivos especializados en distintos tipos de lucha, al frente del que se encontraba más como jefe de mercenarios que como rey ${ }^{25}$. Cuando se hace efectiva su presencia en Occidente y comienza su intervención militar en la península itálica, aparece ante Hierón como un recurso militar importante con el que hacer frente a las intervenciones de otras potencias que tienen intereses en Sicilia.

El último de los ejemplos de hospitalidad tiene como protagonistas a los Pisistrátidas y a los espartanos, siendo interesante, además, porque nos permite plantear la importancia de una segunda característica de este tipo

21 Sobre la naturaleza de esas dinastías y sus poderes efectivos, vid. S. Lancel, Cartago, Barcelona 1994, págs. 112 ss.

22 Sobre los magónidas y su influencia en la vida política de Cartago, vid. E.C. GonzÁLEZ Wagner, Fenicios y cartagineses en la península ibérica, Madrid 1983, págs. 133 ss.

23 Vid. el texto en nota 44.

24 Su oposición a Lisímaco había sido infructuosa, por lo que Pirro ve en la conquista de algunos territorios de Occidente la posibilidad de conquistar y crear un reino propio que de hecho lo conviertan en una suerte de «Alejandro de Occidente». Sobre estas pretensiones y su trayectoria previa en Macedonia, vid. E. Will, Histoire politique du monde hellenistique (I): De la mort d'Alexandre aux avénements d'Antíoco et de Philippe V, Nancy 1966, págs. 85 ss.; 104 ss.

${ }_{25}$ Sobre las características de su poder y de su ejército, vid. N.L.G. Hammond, Epirus, Oxford 1967,568 ss. 
de relaciones, su carácter hereditario. Lo más probable es que este pacto no fuese una iniciativa de los Pisistrátidas, sino una amistad heredada de su padre, pues muestra idénticos objetivos a los desarrollados en el gobierno de Pisístrato. Sabemos, efectivamente, que la política exterior ateniense se mantiene practicamente inmutable durante cerca de medio siglo, con las mismas finalidades e intereses, lo que hace casi imposible distinguir la política de Pisístrato de la de sus hijos. Como veremos más adelante, éste tuvo un especial cuidado en no utilizar la guerra como un medio para favorecer la unidad de los distintos grupos de la polis, y en mantener una política exterior pacífica, en la que se incluían sus especialmente buenas relaciones con el Peloponeso. Esta política de acercamiento, entre otras a Esparta, es mantenida por sus hijos, que probablemente heredaron unas relaciones de hospitalidad que no hicieron más que consolidarla. El texto no es lo suficientemente explícito como para conocer con exactitud cuál es el segundo contrayente del pacto, pues tan solo menciona a los espartanos, aunque por los hechos posteriores parece que debió tratarse de una familia determinada ${ }^{26}$. En cualquier caso, más que los protagonistas cuya elección es similar a las ya vistas, nos importan las consecuencias. La naturaleza hereditaria del pacto favorecería la continuidad de una determinada política exterior, esbozada desde hacía tiempo, que pretendía mantener unas relaciones estables y pacíficas con las potencias más importantes del Peloponeso.

Pero esta extensión familiar era enormemente flexible, pues también admitía otras posibilidades, ya que no sólo los descendientes directos asumieron el cumplimiento de los pactos. Sabemos que cuando los naxios apelaron a Histieo en busca de ayuda, éste se encontraba retenido en la corte persa ${ }^{27}$, por lo que al frente del gobierno de la polis había quedado Aristágoras. Es evidente que un tirano sólo podía dejar en su lugar a una persona de total confianza, que en este caso además de su primo, era su yerno. Es él quien recibe y decide auxiliar a los naxios, asumiendo, como señala Herodoto, el cumplimiento del pacto ${ }^{28}$. Más adelante veremos las razones personales que le llevaron a adoptar esta actitud, lo importante ahora son sus consecuencias. Si de la categoría social de los contrayentes

26 Según la interpretación de WILL. O.c. pág. 645 ss, quien deduce del relato de Herodoto que la hospitalidad y la amistad con los espartanos no debia estar ampliamente extendida y contaría con grupos contrarios a ella, pues al menos Cleomenes era enemigo manifiesto de los atenienses. Sobre la política exterior de Pisístrato vid. Mossé $0 . c .67$ ss. y el texto del pacto, en la n. 932 .

27 Histieo había recibido la promesa persa de que podía fundar una colonia en Mircino, con el fin de explotar sus minas (Hdt. 5.11), sin embargo su creciente poder les pareció una amenaza, por lo que fue llevado a la corte persa en donde permaneció retenido (Hdt. 5.23).

28 Vid. nota 46. 
se derivan sustanciosas ventajas, de su carácter hereditario se derivan otras de no menor importancia. Teóricamente el pacto no decaía con la muerte de los contrayentes, lo que suponía transmitir las obligaciones contraídas a los miembros de una misma familia incluso a lo largo de varias generaciones. Gracias a esta circunstancia el círculo de amistades puede extenderse continuamente, lo que era especialmente interesante en el caso de las tiranías que no se agotaban en la primera generación. Con todo ello se consigue la ampliación de estos círculos de amistades, que no se conciben como relaciones «cerradas» que afectan unicamente a los primeros contrayentes. Hay posibilidades de expansión dentro de los grupos familiares, si sus intereses así lo requieren, con lo que se acrecienta la utilidad del pacto.

La tercera característica de la hospitalidad, que igualmente favorece su utilización política, se deriva precisamente de su naturaleza estrictamente personal y privada. Las relaciones de hospitalidad las contraen individuos que sólo se representan a sí mismos, no a su polis, que -en principio- no se debería ver involucrada en ellos. Por esta razón no requieren una aprobación oficial ni institucional, y por tanto no constituyen una forma de tratado público con otra comunidad. Esta naturaleza privada implica igualmente la ausencia de controles públicos, y la total libertad a la hora de utilizar el pacto. Cada huésped lo puede invocar para sus propios asuntos cuando quiera, sin más «leyes» o normas que las inherentes al mismo, incluso aunque suponga hacerlo en detrimento de los intereses generales. Esto implica una indudable ventaja a la hora de instrumentalizarlos politicamente. Por citar sólo uno de los ejemplos más evidentes, veré el de Histieo de Mileto y los naxios ${ }^{29}$, aunque sus consecuencias son aplicables a todos. No nos encontramos ante un pacto de hospitalidad entre dos Estados, sino entre dos partes «privadas" de origen milesio y naxio, con la peculiaridad de que una de ellas es un tirano, y la otra un grupo de aristócratas que habían controlado el poder hasta hacía poco. Cuando los naxios solicitan la ayuda de su huésped es evidente que no lo hacen como representantes de la polis - entendida en su sentido más conocido de comunidad de ciudadanos- pues no detentan ningún cargo oficial ni magistratura. Son tan solo una parte de la misma, que requiere el apoyo para la facción oligárquica por ellos representada, no para el Estado como tal. Su único objetivo es lograr su restitución en el poder expulsando del mismo a la otra facción, la democrática. Todo ello es posible gracias a que actúan

29 Vid. el texto en la nota 46. 
de forma privada, y que no tienen que someter sus actuaciones al control de un poder que ya no dominaban. La naturaleza privada del pacto permite estos manejos partidarios, aunque tengan una innegable repercusión pública.

Por otro lado, la inexistencia de controles públicos no supone la debilidad del pacto. Es cierto que las relaciones de hospitalidad se basan en la libre voluntad de las dos partes, y que su incumplimiento no podría ser reclamado ante una instancia jurídica o similar. Sin embargo las fuentes nos muestran que el pacto se rompe en muy raras ocasiones, lo que manifiesta la perdurabilidad de estos vínculos, y sólo lo vemos decaer en circunstancias muy peculiares ${ }^{30}$, pues se recurre a otro tipo de sanciones, como la religiosa, para reforzarlo ${ }^{31}$. No es extraño que precisamente para justificar la disolución unilateral del pacto y el ataque a los huéspedes se acuda a recursos de esta naturaleza. Cuando los espartanos deciden invadir Atenas para derrocar a los Pisistrátidas, rompiendo con esta acción la hospitalidad que los unía, pretextan argumentos religiosos ${ }^{32}$. Las circunstancias históricas nos muestran que eran bien distintas las razones, entre las que destacan los manejos de la poderosa familia de los Alcmeónidas que en numerosas ocasiones habían intentado, sin éxito, la intervención espartana en contra de los Pisistrátidas. Su último recurso fue la manipulación del Oráculo de Delfos, que aconsejó a Esparta que derrocase la tiranía ateniense ${ }^{33}$. Es sabido igualmente que este ataque también beneficiaba a Esparta, sin embargo no son ahora las razones históricas

30 Vid. G. Herman, o.c. págs. 70 ss. De los que aquí estamos viendo, se rompen sólo el de los espartanos, que examinaré a continuación, y el de Amasis con Polícrates. Sobre las peculiaridades de la ruptura de este último, que han sido muy discutidas, vid. Mitchell o.c.

31 Vid. por ejemplo Plu. Per. 3.33.

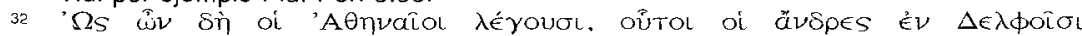

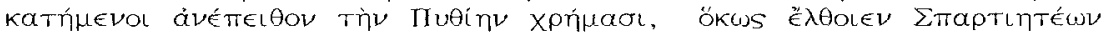

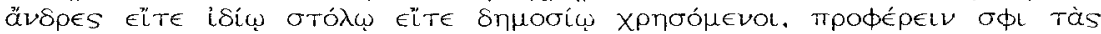

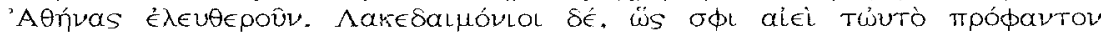

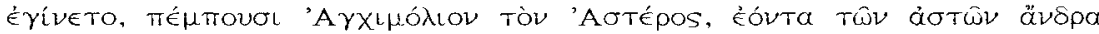

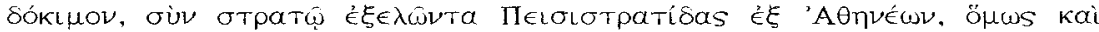

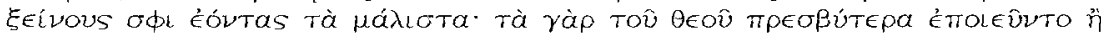

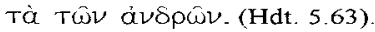

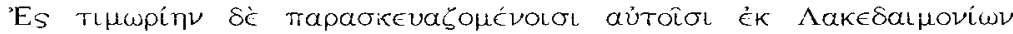

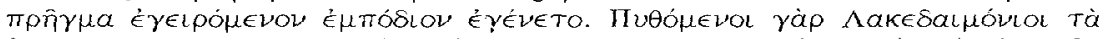

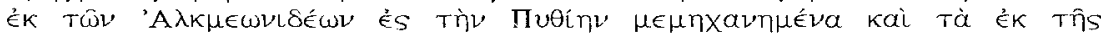

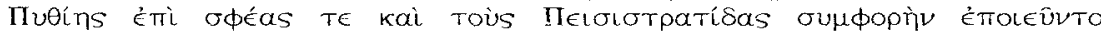

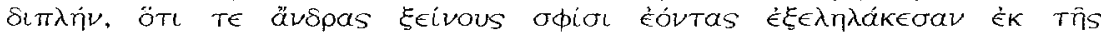

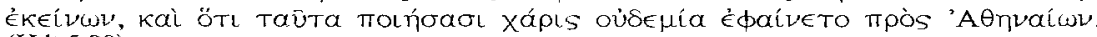
(Hdt 5.90).

33 Los Alcmeónidas tenían claros intereses en Delfos, lo que les ayudó a manipular el Oráculo (vid. D.M. LEwIS, «Cleisthenes and Attica», Historia 15 1963, págs. 37 ss) para lograr su retorno a Atenas con el apoyo espartano. 
que están detrás de esta medida las que nos interesa ${ }^{34}$, sino las que aparecen en el relato de Heródoto. No se considera apropiado justificar la ruptura de un pacto de esta naturaleza por decisiones políticas o estratégicas, sino por algo que está más allá de su propia capacidad de decisión. Es la "voluntad divina», expresada a través del Oráculo de Delfos, la que puede propiciar que un pacto de hospitalidad, en principio inviolable y sagrado, sea roto por una de las partes.

Las características de la hospitalidad que hasta ahora hemos visto suponían para los tiranos disponer de un valioso recurso político, con la creación de alianzas duraderas, estables y poderosas. En muchos casos, como veremos a continuación, el pacto fue invocado para servir a unos intereses precisos, lo que nos permite ver además sus múltiples funciones. Una vez más la hospitalidad se adapta a las necesidades de cada tirano y a las distintas circunstancias históricas. Vemos así que puede utilizarse como un medio de reforzar y consolidar el poder de dos tiranos, como es el caso de Periandro y Trasíbulo. En otros casos funcionan como un tratado "de facto" de política exterior, que vincula a dos Estados, no oficialmente, sino a través de la amistad especial que une a sus máximos representantes, como hicieron los Pisistrátidas con los espartanos o Polícrates con Amasis, en cada caso con intereses distintos, estratégicos y económicos respectivamente. En otras ocasiones esta ayuda se materializa en un apoyo militar, lo que fue especialmente importante en el caso de los tiranos sicilianos, Hierón y Terílo, cuyo poder estaba basado en gran medida en apoyos de esta naturaleza. Esta ayuda militar se mezcla con la intervención en las luchas internas de una polis en el caso de Histieo y los naxios.

La ayuda que Periandro presta a Trasíbulo a la hora de consolidar su poder es un primer ejemplo de esta utilización política. Las ventajas de su relación se ponen a prueba durante un estado de guerra casi permanente que padecía Mileto. Tras años de luchas que suponían la devastación anual de las cosechas milesias a manos de las tropas lidias, se produce un hecho inesperado que cambiará totalmente la situación. La

34 Como indica E. WILL (Korinthiaka. Recherches sur I'histoire et la civilisation de Corinthe des origines aux guerres médiques, París $1955,645 \mathrm{ss}$.) las razones por las que se produce su ataque serían políticas, pues Cleomenes pretendía incluir a Atenas en una alianza más amplia, para lo que sería indispensable el cambio de régimen. Para P. CARTLEdGE (Sparta and Lakonia, Londres 1979 , págs. $143 \mathrm{ss}$ ), son también obvios los intereses personales, pues Cleomenes se aprovecha de un oráculo favorable que coincide con sus objetivos. Sobre la figura de este rey, el primero verdaderamente histórico de Esparta, pues sus hechos se pueden datar con bastante precisión, y con una trayectoria bastante polémica, vid. P. CARLIER, «La vie politique à Sparte sous le règne de Cléomene |», Ktema 7 1977, págs. 65-84. 
destrucción accidental del templo de Atenea causada por los lidios y el "castigo divino" que, como consecuencia, padecerán las tropas invasoras, les obliga, como último recurso, a la consulta de la Pitia, que ordena la inmediata recontrucción del edificio sacro. Es aquí en donde entra en juego la amistad de Periandro, quien logra enterarse de esta respuesta y -según nos aclara Herodoto- en función de las relaciones de hospitalidad que mantenía con Trasíbulo, se la comunica para que se aproveche politicamente de la situación, como así ocurre ${ }^{35}$. Las consecuencias son obvias, pues Trasíbulo pasa de detentar una posición débil, debido a la inestabilidad del Estado con las constantes guerras, a afianzarse en el mismo.

En el caso de los Pisistrátidas nos encontramos con unas relaciones de hospitalidad que, de hecho, pretenden servir como un tratado de política exterior. En cualquier caso las pretensiones de desarrollar una política exterior que garantice unas relaciones pacíficas con un gran número de poleis, incluída Esparta, están presentes ya con Pisístrato. Sabemos que entre los numerosos Estados con los que estableció contactos amistosos se incluían, en primer lugar, los del Peloponeso, con los que en general mantuvo unas buenas relaciones. En parte esto se debió a sus relaciones personales, pues de Argos, por ejemplo, procedía su segunda mujer, en tanto sus vínculos con otros tiranos - Periandro de Corinto- favorecieron igualmente su política ${ }^{36}$. Pero también con otras poleis importantes como Megara o la propia Esparta desarrolló una política exenta de confrontaciones ${ }^{37}$. Estos principios que rigen las relaciones externas de la tiranía ateniense, y que suponen establecer unos vínculos con las poleis más destacadas para evitar cualquier tipo de enfrentamiento, se afianzan

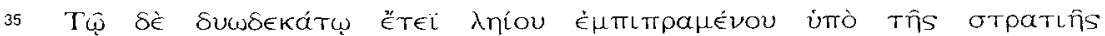

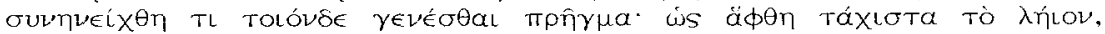

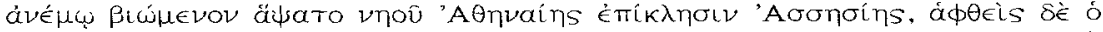

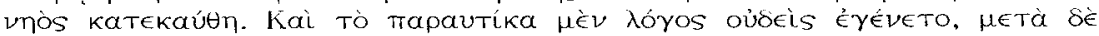

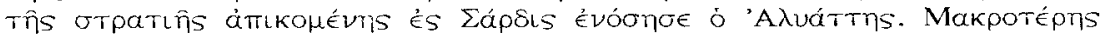

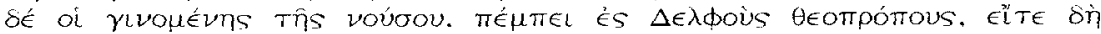

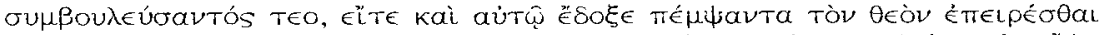

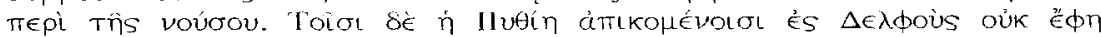

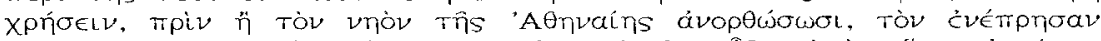

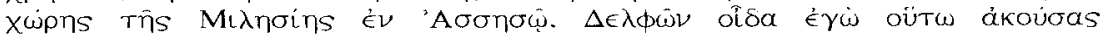

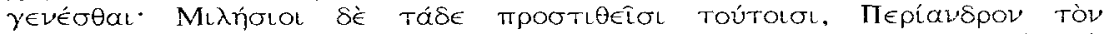
Kuфié

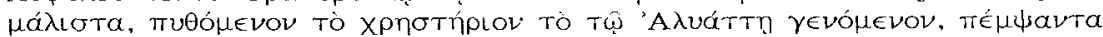

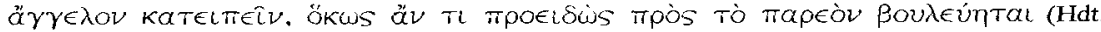
1. 19-20)

36 Sobre sus relaciones con otros tiranos vid. también nota 4.

37 Como señala Mossé, Pisístrato había concluído una serie de alianzas personales que se convirtieron, cuando consolidó su tiranía, en política de Estado. Sobre las orientaciones básicas de su política exterior vid. Mossé o.c. p. 51 ss. 
en el caso espartano con la hospitalidad. Los Pisistrátidas pretendían continuar esa política, ayudados por unas relaciones personales heredadas que deberían jugar a su favor en caso de que se plantease algún problema; aunque como ya hemos visto, por diversos intereses fracasaron.

Idéntico interés tiene el pacto entre Polícrates de Samos y el faraón Amasis, aunque en este caso los fines de este tratado deben de entenderse no sólo como un recurso político para afianzar su poder u obtener un aliado externo, sino con una clara finalidad económica. La decisión de Polícrates se inscribe dentro de la expansión económica de la isla, sostenida por su flota. No debemos olvidar que ésta era una de las dos mayores de Jonia, y que parte de la política de este tirano estuvo dirigida a su consolidación, como lo demuestra la ampliación del puerto. Los intereses comerciales de la isla eran muy amplios, y en ellos ocupaba un papel importante Egipto. Los intercambios que Samos mantuvo con este Estado son bien conocidos antes del acceso al poder de Polícrates, con unos intereses muy claros centrados en Naucratis. La relación personal que el tirano establece con Amasis no pretende, en principio, sino afianzar esos intereses ${ }^{38}$.

También estas relaciones fueron un buen recurso al que apelar en caso de conflictos armados, lo que se ve especialmente bien en el caso de los tiranos de Sicilia. Los dos ejemplos que aquí veremos reflejan el cruce de intereses externos a la isla, con las intervenciones de cartagineses y romanos. Los primeros habían mantenido una clara intervención en los asuntos de la isla con el objetivo básico de evitar la consolidación de un poder fuerte que pudiese crear un Estado territorialmente amplio y peligroso para sus intereses. Las formas de intervención fueron diversas, desde la intromisión en sus asuntos internos hasta la lucha directa, como en el caso del enfrentamiento con Agatocles ${ }^{39}$. Por su parte la intervención romana se produce en el marco de su expansión hacia el sur de la península itálica. Aunque ambos pactos se producen en un período bastante alejado en el tiempo, la utilidad del pacto es idéntica para ambos tiranos, pues lo que pretenden esencialmente es disponer de un apoyo militar externo que viene ofrecido por su huésped.

38 Vid. Astin o.c. pág. 293. Sobre el poder naval de Samos, vid. las observaciones de Ch. J. HAAS, "Athenian naval power before Themistocles", Historia 34 1985, págs. 29-46. Las instalaciones comerciales de Samos debían estar situadas en la región del Delta del Nilo, aunque con Amasis probablemente se desviaron a Naucratis. En cualquier caso los intercambios fueron siempre muy importantes, sobre todo en lo que se refiere al aceite de oliva, vid. un análisis más detallado en G. Shipley, A History of Samos (880-188 BC), Oxford 1987, págs. 86 ss.

39 GONZÁlez WAGNER O.c. págs. 330 ss. 
Terílo de Himera pretendía el socorro militar de Amílcar ante la amenaza de otro tirano, Gelón, que lo había expulsado de su polis. Himera era una de las comunidades con mayores intereses comerciales debido a su situación estratégica. Situada en las rutas que comunicaban Etruria, Cartago e incluso la península ibérica, disfrutó muy pronto de una gran prosperidad económica ${ }^{40}$. Su independencia, sin embargo se ve amenazada por la situación histórica que se vive tras producirse la decadencia etrusca, cuando comienza el auge de la Siracusa dirigida por Gelón. Cuando éste consigue unificar por primera vez las poleis de la isla creando un Estado territorial amplio, Himera se presenta como uno de los últimos obstáculos. Después de controlar —con el que entonces era el ejército más poderoso de la isla - las poleis más importantes, incluidas Gela, Megara y Siracusa - a la que convierte en base de su flota- se dirige a los pocos Estados que aún son independientes, como Himera. La debilidad de la posición de Terilo queda de manifiesto en que sólo podía contar con la ayuda de Anaxilos de Region, debido también a los lazos personales que los unían ${ }^{41}$, por lo que la única posibilidad de hacer frente a Gelón es recurrir al apoyo externo representado por Cartago. Es aquí en donde entra en funcionamiento el pacto de hospitalidad, pues Terílo pide el auxilio cartaginés. Éste se llega a concretar en la conocida expedición que fue un fracaso total para los intereses cartagineses ${ }^{42}$. La conclusión que nos importa, sin embargo, es que Terílo no pide ayuda al Estado, a Cartago, sino a una persona concreta, a Amílcar, invocando para ello la hospitalidad que los unía ${ }^{43}$.

40 Vid. T.J. Dunbabin, The Western Greeks. A History of Sicily and South Italy from the Foundations of the Greek Colonies to 480 BC, Oxford 1968, pág. 300 .

41 Anaxilos era su yerno, para otros ejemplos de matrimonios entre tiranos y su utilización vid. L. GERnET, "Matrimonios de tiranos", en Antropología de la Grecia Antigua, Madrid 1980, págs. 299-322.

42 Y que la tradición historiográfica griega trató de convertir en un intento de «esclavizar a los griegos". Vid. el análisis de esta tradición así como la del relato de Herodoto en C.R. Whittaker, "Carthaginian Imperialism in the fith and fourth Centuries", en P. GARNSEY, C.R. WHITTAKER (edd.), Imperialism in the Ancient World, Cambridge 1978, págs. 60-90

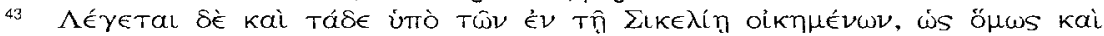

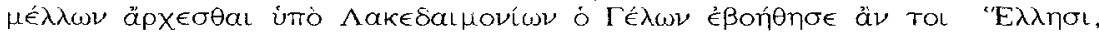

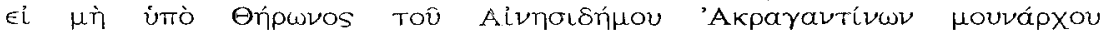

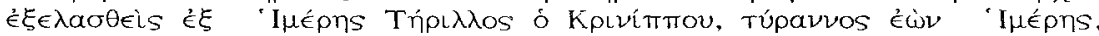

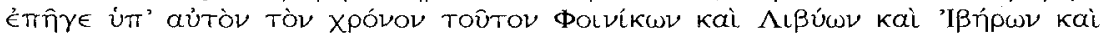

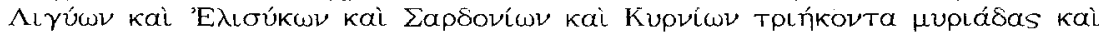

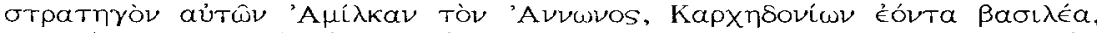

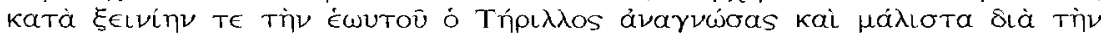

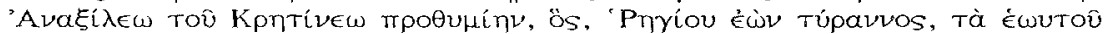

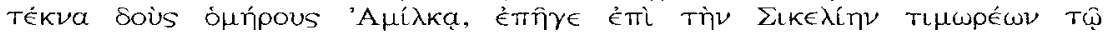
$\pi \in \mathcal{V} \theta \in \hat{p}^{-} \cdot$ (Hdt. 7.165). 
Los objetivos buscados por Hierón en su pacto de hospitalidad con Pirro es similar - aunque se produce dos siglos más tarde-por lo que no me detendré demasiado en él. Los numerosos intereses contrapuestos en la isla, que mantenía un delicado equilibrio entre griegos, romanos y cartagineses, junto a la inestabilidad del poder del propio Hierón, hacían aconsejable el reforzamiento de su poder ${ }^{44}$. Para ello escogió a un jefe de mercenarios, con un buen ejército y que era bien conocido por su intervención en la península itálica, aunque su actuación en Sicilia frustraría rapidamente las esperanzas griegas puestas en él ${ }^{45}$.

El último caso, el de Histieo y Aristágoras - que es quien asume el cumplimiento del pacto- presenta unas características claramente personales, aunque curiosamente es el que tendrá una mayor repercusión en la historia griega. Los naxios piden ayuda para retomar el poder en la polis, lo que provoca en la isla no sólo una intervención milesia, sino también la ayuda persa ${ }^{46}$. Las consecuencias de esta fallida intervención terminarán, como es bien sabido, en los inicios de la revuelta jonia que dará lugar a las Guerras Médicas. Es un episodio suficientemente estudiado por esta razón, pero no en lo que se refiere al aspecto que aquí nos interesa, el de la hos-

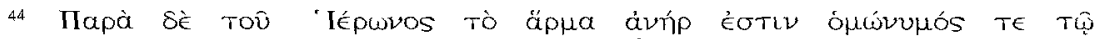

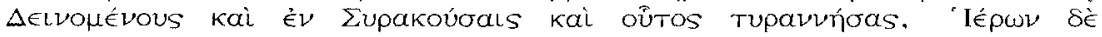
'́ka

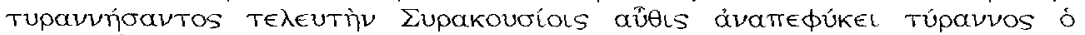

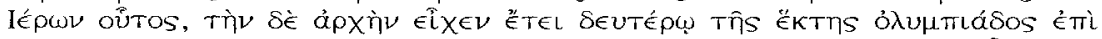

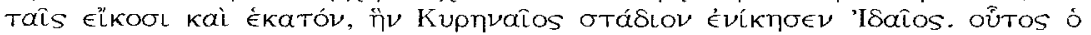

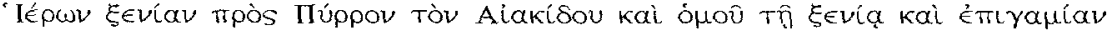

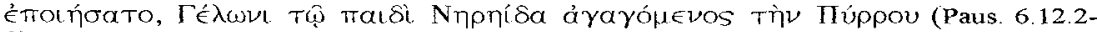
3).
}

45 Sobre su relación con las poleis griegas, vid. WiLL o.c. (1966) págs. 106 ss. No es fácil establecer los movimientos de Pirro en su enfrentamiento con Roma, pero se conocen mejor la posición de Roma en Sicilia y sus motivos, vid. D. MuSTI, "La spinta verso il sud: espansione romana e rapporti "intervenzionisti", en A. Momigliaino, A. Schiavone (edd.), Storia de Roma (1): Roma in Italia, Turín 1988, págs. 539 ss.

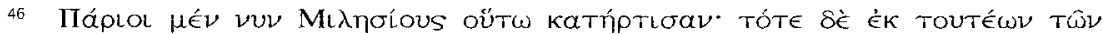

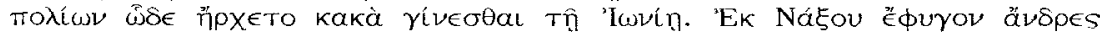

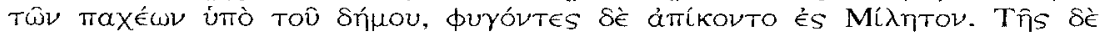

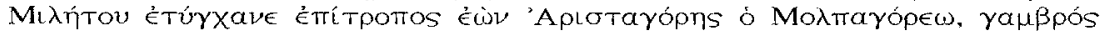

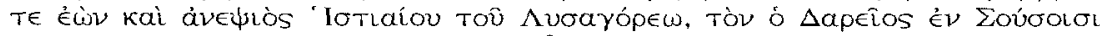

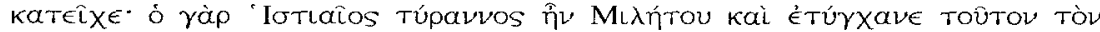

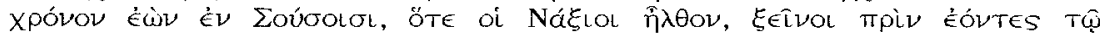

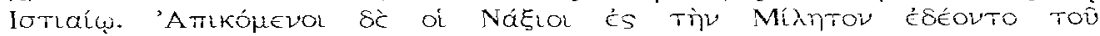

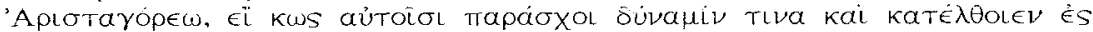

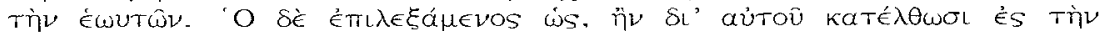

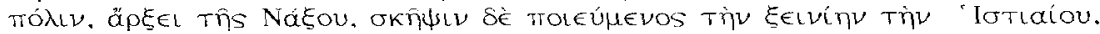

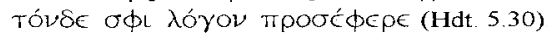


pitalidad ${ }^{47}$. El retrato que se deriva de la narración de Heródoto, que tiene en general todos los visos de ser veraz ${ }^{48}$, nos muestra intereses exclusivamente personales en la acción de ambas partes. Por un lado los naxios no pretenden un apoyo para defender a la polis de un peligro externo, sino exclusivamente defender los privilegios políticos que habían perdido con el cambio del régimen político. Por otra parte también Aristágoras parece moverse con idénticos fines, si bien no ha sido muy fácil establecer cuáles son. En el relato de Heródoto aparece principalemente su interés por acrecentar su poder, haciéndose con el control de Naxos, lo que le llevaría quizás a instalar en ella su propia tiranía. También se ha señalado su enfrentamiento personal con Histieo, hasta el punto de que sus movimientos posteriores estarían dirigidos no sólo a luchar contra los persas, sino a acabar politicamente con él ${ }^{49}$. En todo caso el texto es quizás el ejemplo más claro de utilización personal de la hospitalidad, sin que se busque con ello ningún beneficio para las poleis respectivas. Se mezclan la ambición por el poder en ambas partes con la traición y las injerencias de los persas, que provocan una intervención armada con las consecuencias conocidas.

A lo largo de estos ejemplos se pone de manifiesto la gran utilidad que este tipo de pactos tiene para un tirano. Las relaciones de hospitalidad le permiten crear alianzas con otros individuos que controlan el poder en su comunidad, detenten o no un poder institucionalizado, sean griegos o sean «bárbaros». Son relaciones duraderas y estables, que se extienden gracias a su carácter hereditario y que son frecuentemente invocadas para su propio beneficio. Nos encontramos ante multitud de causas en las que puede ser utilizado: en tiempos de paz o de guerra, para hacer frente a amenazas externas o internas, como un apoyo militar, estratégico o económico, para garantizar, consolidar o extender su poder... Todo esto hace de estas relaciones un valioso instrumento político personal, que, dada la naturaleza del poder de los tiranos y su conformación al margen de las instituciones de la polis, no dudaron en utilizar.

47 Como es sabido es éste uno de los asuntos más debatidos por los historiadores actuales en los últimos años, debido a las innegables repercusiones que tuvo en las relaciones entre griegos y persas. En la monografía de P. Tozzı, La rivolta ionica (Biblioteca di Studi Antichi), Pisa 1978 , se pueden encontrar las referencias más destacadas hasta ese momento, que ya superaban las 100, y que se han seguido incrementando desde entonces, como lo muestran algunas de las que aquí se citan.

48 Sobre la veracidad, asi como sobre el interés del ataque, vid. H.T. WALlingA, "The Ionian Revolt», Mnemosyne 37 1984, págs. 401-437. Para otros aspectos del relato de Herodoto vid. M. LANG, "Herodotus and the Ionian Revolt», Historia 17, 1968, págs. 24-36 con la réplica de G.A.H. CHAPMAN, "Herodotus and Histiaeus' Role in the Ionian Revolt», Historia 21 1972, págs. 546 ss.

49 Vid. la exposición de los distintos motivos en P.B. MANVILLE, «Aristagoras and Histiaios: The Leadership Struggle in the Ionian Revolt», CQ27 1977, págs. 80-91. 